\title{
O ULYSSES DE JOYCE REESCRITO POR HOUAISS: PROBLEMAS DE TRADUÇÃO E AS SOLUÇÕES ENCONTRADAS ${ }^{1}$
}

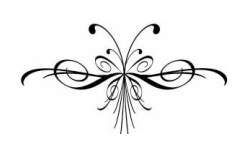

\author{
Áureo Lustosa Guérios Neto
}

Resumo: O objetivo do presente trabalho é o de avaliar criticamente os méritos e deméritos da tradução brasileira do Ulysses de James Joyce feita por Antônio Houaiss. O recorte do corpus que serve de base para a reflexão crítica é constituído pelos três primeiros episódios do Ulysses, no original e na tradução. Já a referência teórica sobre a qual se constrói a argumentação é o texto $O$ Discurso no Romance de Mikhail Bakhtin. A reflexão não se circunscreve apenas ao texto traduzido em si, mas também toma como relevantes alguns dados biográficos que ligam Houaiss ao Ulysses. A argumentação do trabalho caminha dualmente, levantando pontos positivos e negativos da tradução em exame. Entre os pontos positivos foram levantados: a erudição afiada de Houaiss, o resultado final admirável dadas as condições precárias de trabalho, e a divulgação de

\begin{abstract}
Our scope in the following work is to evaluate critically the virtues and vices of the brazilian translation of James Joyce's Ulysses done by Antônio Houaiss. The corpus underlying the discussion consists of the first three episodes of the book, in its original form and in translation. The theoretical support on which the arguments are built comes from Mikhail Bakhtin's Discourse in the Novel. Our critique is not restricted to the translation itself but it considers as relevant some biographical facts which connect Houaiss to Ulysses. The arguments try to present, alternatively, the merits and demerits of the translation. Some of the translation's strong points are: Houaiss' sharp erudtion, the admirable final result given the precarious conditions of work, and the marketing of the book. The weak points that were identified are: Houaiss' limited experience as a
\end{abstract}

${ }^{1}$ Trabalho elaborado sob a supervisão do professor Caetano Waldrigues Galindo (DELIN), apresentado à Coordenação de Iniciação Científica e Integração Acadêmica da Universidade Federal do Paraná, por ocasião de conclusão das atividades de Iniciação Científica, 2009. 
uma obra tão importante. Já entre os pontos negativos foram identificados: a pouca experiência de Houaiss como tradutor, sua criação de uma fala coloquial artificial, o descuido editorial, e as poucas notas de rodapé da edição. Este trabalho se conclui, então, qualificando o projeto tradutológico de Houaiss, ainda que muito audaz, como paradoxal e pouco congruente.

Palavras-Chave: Joyce, Houaiss, Bakhtin, Ulysses, tradução translator, the artificial colloquialisms that he produced, the precarious editorial work, and the almost non-existence of explanatory notes. We conclude the article by qualifying Houaiss' translation as contradictory and inconsistent, even though it was an audacious one.

Keywords: Joyce, Houaiss, Bakhtin, Ulysses, translation

$\mathrm{O}$ Ulysses, obra máxima de James Joyce, quando publicado, em 1922, imediatamente mostrou ser um divisor de águas. Nesse livro, Joyce concentrou todas as conquistas estilísticas e técnicas de que se havia tido notícia até então. Antes dele, outros romancistas haviam revolucionado a escrita romanesca. Flaubert, autor de grande influência sobre Joyce, criou escola ao introduzir no romance o narrador neutro, não opinativo, e cujo discurso se funde e confunde com o das personagens através do uso narrativo do discurso indireto livre. Joyce soube utilizar muito bem essas conquistas de Flaubert e levou-as adiante. Outra ferramenta essencial para a tessitura do Ulysses é o fluxo de consciência, também chamado de monólogo interior. O fluxo de consciência, criado por Eduard Dujardin, mas adotado e refinado por Joyce, é mais uma das ferramentas que o romance europeu mal conhecia quando Joyce terminou esse livro.

O Ulysses inaugura, em literatura, o método mítico, assim batizado por T. S. Eliot. Adotando como paralelo a Odisséia, de Homero, Joyce compôs um novo romance que se baseia e encontra correlações com o texto de outrem. O método pode, inclusive, ser definido como muito mais que "intertextual". O Ulysses reinterpreta e modifica o texto em que se baseia, o mesmo se dá, igualmente, em sentido inverso. Embora o conhecimento profundo da Odisséia não seja imprescindível para a compreensão do Ulysses, é altamente recomendável que o leitor esteja familiarizado com o texto base.

No Ulysses o método mítico funciona através de episódios: um episódio da Odisséia, corresponde a um episódio no Ulysses. Dos dezoito episódio (ou capítulos) do Ulysses apenas um não é baseado em um acon- 
tecimento da Odisséia, mas em outro texto épico grego Jasão e os Argonautas de Apolônio de Rodes ${ }^{2}$. Assim, os três primeiros episódios do Ulysses constituem a Telemaquia, grupo que se encontra nos quatro primeiros episódios da Odisséia. Na Odisséia, a Telemaquia narra as aventuras de Telêmaco, filho de Odisseu, em busca de informações sobre o pai e descreve a ação dos pretendentes em Ítaca, cortejando Penélope e usurpando as posses de Odisseu. Já no Ulysses, na Telemaquia acompanhamos Stephen Dedalus, o Telêmaco moderno, por algumas horas. Stephen se considera usurpado por Buck Mulligan (pretendentes), tem uma conversa com o diretor da escola em que trabalha, Mr. Deasy (Nestor), e passeia pela praia imerso em pensamentos (Proteu). As correspondências com a Odisséia não param por aí: o quarto episódio remete a Calypso, o quinto aos Lotófagos, o sexto ao Hades, e assim por diante até a conclusão da narrativa.

Além disso, cada um dos episódios é uma unidade estilística completa e Joyce varia inteiramente as técnicas narrativas empregadas de um episódio ao outro. No Ulysses, a cada episódio, o leitor tem a impressão de começar um novo livro. No entanto, Joyce rapidamente esgota as técnicas existentes até aquele momento e passa, então, a libertar sua capacidade inventiva. Assim, cria o que alguns críticos chamarão de "prática de terra devastada": a cada episódio o autor propõe uma técnica romanesca nova, para em seguida explorar todas as suas possibilidades, levando-a à exaustão. Em seguida, ele cria e esgota uma nova técnica, repetindo o processo até o fim do livro. É essa prática de terra devastada que levou T. S. Eliot a declarar que com o Ulysses Joyce teria: "provado a esterilidade do estilo, destruído a literatura existente antes dele e posto um fim a sua carreira como romancista". De fato, todo o conceito de vanguarda em literatura terá de ser redefinido na vida pós-Joyce. É isso que leva Augusto de Campos, em sua crítica à tradução de Houaiss, a declarar:

O Joyce de Ulysses e Finnegans Wake divide a história do romance em antes e depois, a. J., d. J., antes de Joyce, depois de Joyce. E, tudo bem pesado, talvez nem haja "depois"; talvez, depois de Joyce, o romance já não deva ser romance, mas uma outra coisa, pois com Ulysses Joyce escreveu, na expressão de Harry Levin, "um romance para acabar com todos os romances", deixando todo prosador lúcido, posterior a ele, num incômodo mas fascinante "beco sem saída"... [...] Um escritor atual que não tenha lido Joyce é mais ou menos como um físico que ignore Einstein ou um sociólogo que não tenha tomado conhecimento de Marx.

\footnotetext{
${ }^{2}$ Diga-se de passagem, que esse texto do século III a.c. se relaciona intimamente com os textos homéricos, através da linguagem arcaizante, modelos de composição, modelos de personagens, mitos trabalhados etc., constituindo dessa forma uma referência indireta à Ilíada e à Odisséia.
} 
As técnicas novas ainda se desdobram em um uso vasto de diversos gêneros literários: o episódio 13, Nausíca, é narrado de acordo com a prosa de "um romance para moçoilas", enquanto que o episódio 15, Circe, faz uso de texto teatral.

Todas essas técnicas novas e brincadeiras com gêneros fazem do Ulysses um livro complexo, de digestão difícil e trabalhosa. Em certa medida, essa não é uma obra para se enfrentar solitariamente. Para uma compreensão profunda e abrangente do livro, o auxílio de aparato crítico, de notas de rodapé (ao texto e à tradução), de explicações de cunho histórico, biográfico e bibliográfico é indispensável.

A orquestração de todas as técnicas de representação literária empregadas por Joyce cria espaço para uma série de "vozes", distintas entre si, que se digladiam num palco comum. As vozes das personagens são muito idiossincráticas, uma vez que Joyce é particularmente competente em suas representações do discurso oral. Por exemplo, os três personagens atuantes no primeiro episódio, Dedalus, Mulligan e Haynes, são completamente individualizáveis via seu modo de expressão.

Para além da voz dos personagens, a voz do narrador desempenha um papel fundamental no coro. O narrador joyceano é, em princípio, neutro. No entanto, ele é facilmente influenciado pelo discurso das personagens. Assim, se o narrador descreve um ambiente em que se encontra Stephen Dedalus, uma descrição que inicialmente era neutra pode começar a englobar elementos típicos da voz de Dedalus. Sempre, porém, no discurso do narrador. Mais uma das invenções de Joyce: seu narrador é influenciável. Mais do que isso: o discurso do narrador também pode ser permeado pelo discurso das personagens através do fluxo de consciência. Dessa forma, em meio a um parágrafo em que quem fala é a voz neutra do narrador, surge um período que claramente não pertence a essa voz, mas pertence a outrem. Um exemplo:

E pondo-se o colarinho duro e a gravata rebelde, falava-lhes, censurando-os, e à sua corrente de relógio pendida. Suas mãos mergulhavam e remexiam pelo seu torso no que chamava por um lenço limpo. Remordida do imo-senso. Por deus, o que importa é trajar a personagem. Quero luvas violeta e botinas verdes. Contradição. Contradigo-me a mim mesmo? Muito bem, então, contradigo-me a mim mesmo. Malachi Mercurial. Um mole projéctil negro desvoou de suas mãos facundas. (página 27, meus grifos)

No exemplo acima, percebe-se claramente a intromissão abrupta da voz de Stephen Dedalus no discurso do narrador. Na citação, a intromissão foi por mim destacada em itálico, mas isso não acontece nunca na narrativa. Vejamos o que acontece. O narrador descreve Buck Mulligan enquanto ele, ao mesmo tempo, se veste e conversa com Dedalus e Haynes. No entanto, a voz do narrador é cortada ao término do segundo período pelo fluxo de consciência de Dedalus que começa com "Remor- 
dida do imo-senso" e se fecha em "Malachi Mercurial". Uma frase como "Quero luvas violeta e botinas verdes" não faz parte do discurso do narrador e o leitor rapidamente percebe isso. Essa é inclusive uma das grandes dificuldades do Ulysses: o leitor percebe que uma voz se intrometeu e tomou o lugar do discurso do narrador; no entanto, ele perde o referencial e não consegue dizer com segurança quem está falando. A partir da última fala de Dedalus, "Malachi Mercurial", o narrador reassume seu posto, dizendo que o chapéu (mole projéctil negro) de Dedalus caiu de suas mãos. O exemplo utilizado é uma amostra pequena e até mesmo simples da grande mistura de vozes que tem lugar no Ulysses. Justamente por isso, o Ulysses parece clamar pelas teorias de representação literária de Bakhtin, ou melhor, o Ulysses parece ser o melhor exemplo de aplicabilidade dessas teorias.

\section{Bakhtin e o Ulysses}

Em $O$ discurso no romance, Mikhail Bakhtin procura lançar as bases para uma nova "estilística do romance". Para fazer isso, Bakhtin define, logo no início do texto, o que entende por romance. Segundo o estudioso, "o romance é uma diversidade social de linguagens organizadas artisticamente, às vezes de línguas e de vozes individuais". Por isso, "o romance, tomado como conjunto, caracteriza-se como um fenômeno pluriestilístico, plurilíngue e plurivocal'. O romance é visto por ele como uma combinação de estilos que dá, necessariamente, vazão a diversas vozes que por sua vez se estratificam internamente de modo diversificado. O estudioso tenta, então, desfragmentar o romance em unidades básicas:

(1) a narrativa direta e literária do autor (em todas as suas variantes multiformes);

(2) a estilização de diversas formas da narrativa tradicional oral;

(3) a estilização de diversas formas da narrativa (escrita) semiliterária tradicional (cartas, diários, etc.);

(4) Diversas formas literárias, mas que estão fora do discurso literário do autor: escritos morais, filosóficos, científicos, declamação retórica, descrições etnográficas, informações protocolares, etc.

(5) O discurso das personagens estilisticamente individualizados.

Mais adiante no texto, Bakhtin faz uma revisão histórica do desenvolvimento do romance e identifica duas linhas que correm paralelas; ele não nomeia as duas correntes, chama-as apenas de primeira linha e segunda linha.

Os romances da primeira linha seriam aqueles que "têm a pretensão de organizar e de ordenar estilisticamente o plurilinguismo”. Devido à 
sua natureza regulamentadora, os romances dessa linha normalmente têm pretensões didascálicas. Eles pretendem ensinar o leitor a se portar em sociedade, escrever uma carta, ou a organizar um discurso retoricamente. Motivado por isso, o discurso dos romances da primeira linha abusa de eufemismos e se opõe a expressões grosseiras. Os romances dessa linha vêem no "bom-tom" e no "bom-estilo" as únicas categorias possíveis para a produção literária. Infelizmente, Bakhtin não oferece exemplos de romances que pertencem à primeira linha. Exemplifico-o aqui, portanto por minha conta e risco, com o Decameron de Boccaccio. O texto de Boccaccio, embora não possa apropriadamente ser chamado de romance, tem diversas pretensões normativas em todo tipo de campo: religiosa, moral, sexual, discursiva, retórica, etc. Não é à toa que justamente o Decameron se tornou a grande obra de referência para a produção literária italiana a partir de $1525^{3}$.

Os romances da segunda linha, que é largamente mais discutida e exemplificada por Bakhtin, são aqueles que pervertem através da paródia a proposta de representação literária áulica dos romances da primeira linha. Assim, essa linha de romances privilegia o grosseiro, o sórdido, o prosaico, para com isso destruir o plano elevado. Bakhtin usa como exemplo máximo desse modelo paródico, Rabelais e Cervantes, mas também discorre abundantemente sobre Sterne e Jean Paul. Para o estudioso, a segunda linha desempenha um papel crucial na formação do romance como gênero máximo da prosa: "Ela [a segunda linha] revela de uma vez por todas as virtualidades contidas no gênero romanesco; nela o romance tornou-se aquilo que é."

O pesquisador russo também sublinha bastante o fato de que o romance é permeável por todo tipo de gêneros de fala e escrita: ele pode englobar gêneros díspares como cartas, diários, biografias, poesia, etc. Diz Bakhtin: "Em princípio, qualquer gênero pode ser introduzido na estrutura do romance". Em um romance como o Ulysses, em que cada episódio tem um estilo diferente e em que uma série de gêneros comparecem (telegrama, teatro, canção, texto científico, etc.), essa possibilidade de intercalar gêneros é muitíssimo usada.

Bakhtin infelizmente não nomeia Joyce em seu texto. No entanto, ele aborda muito a produção de Laurence Sterne, escritor que teve profunda e definitiva influência na formação de Joyce como romancista. A influência de Sterne, somada ao fato de que o Ulysses obviamente se encaixaria na segunda linha, nos permite concluir que, embora não trate di-

\footnotetext{
${ }^{3}$ Data de 1525 a publicação de Prose nelle quali si ragiona della volgar lingua, um tratado de autoria de Pietro Bembo usualmente considerado a primeira gramática normativa da língua italiana. Nesse tratado Bembo estabelece as "regras para a composição literária e linguística" e toma como modelos a serem imitados, Petrarca, na poesia, e Boccaccio, na prosa. Isso não apenas aponta para as pretensões normativas de Boccaccio, mas também as ratifica.
} 
retamente da produção joyceana, o texto de Bakhtin pode referir-se indiretamente ao texto de Joyce. Na verdade, mais de um comentador já se surpreendeu com o fato de que Bakhtin nunca tenha citado Joyce, pois o autor irlandês parece ser, no século XX, o melhor exemplo da aplicabilidade da teoria de orquestração de vozes e de plurilinguismo proposta pelo estudioso russo. É justamente esse possível diálogo profundo entre os dois autores o conteúdo da tese Abre aspas: a representação da palavra do outro no Ulysses de James Joyce e seu possível convívio com a palavra de Bakhtin, de Galindo, o qual pretendemos resgatar para a discussão da tradução de Houaiss.

\section{Telemaquia: Período de Escolhas}

Para atingir os objetivos de crítica de tradução que norteiam o presente trabalho, escolhemos analisar os três primeiros episódios do Ulysses. Estes episódios constituem uma unidade fechada dentro do livro, a Telemaquia. A escolha desse grupo não é arbitrária e se deu por entendermos que os episódios em questão, não apenas são ilustrativos de todo o livro no que diz respeito às técnicas literárias empregadas, como também oferecem dificuldades de tradução que alimentam nossa discussão. Além disso, a grande quantidade de trocadilhos, citações inter e intratextuais, construções paródicas etc., também foi decisiva em nossa escolha.

A Telemaquia é dedicada a um único personagem, Stephen Dedalus. Ele é um personagem algo marginalizado e amargurado, mas que detém uma erudição assombrosa. Como Dedalus influencia enormemente o tom adotado pelo texto, esses três primeiros episódios acabam se tornando um desafio para o leitor de primeira viagem. As dificuldades que o leitor enfrenta perpassam a erudição afiadíssima de Dedalus, que usa diversas línguas, reflete sobre conceitos filosóficos e teológicos, e pensa constantemente na história da Irlanda. Além disso, o leitor enfrenta um problema que é essencialmente vocabular: o vocabulário de Dedalus é enorme, tornando trabalhoso para o leitor manter-se a par de tudo que ocorre em torno do personagem.

Entendemos que se para o leitor não familiarizado com o Ulysses as dificuldades são numerosas e volumosas, para o tradutor, que teria a obrigação de ser o leitor ideal do texto, elas não serão menores. Com isso em mente, chegamos à conclusão de que a escolha desses três primeiros episódios favorece nosso objetivo de rastrear o projeto tradutório de Houaiss. 


\section{Houaiss Tradutor}

Quando publicado em 1922, o Ulysses imediatamente causou furor no mundo literário da época, por diversos motivos. A obra foi ovacionada por poucos como genial, muitos reclamaram da dificuldade demasiada que impossibilitava a leitura, e uma maioria protestou contra a falta de pudor do livro, o que se refletiu em sua proibição por "imoralidade" por mais de uma década, tanto na Inglaterra quanto nos Estados Unidos

No Brasil, o livro foi publicado apenas em 1966, traduzido por ninguém menos que Antônio Houaiss. Houaiss era já na época um dos intelectuais mais eminentes do país, e, como encontrava-se desempregado no período imediatamente anterior ao da tradução, aceitou trabalhar segundo regime de trabalho não muito amigável proposto pela Civilização Brasileira. Houaiss deveria traduzir o Ulysses em apenas um ano, projeto que ele, surpreendentemente, conseguiu levar a cabo. Há de se reconhecer esse mérito: Houaiss conseguiu traduzir uma obra de enorme complexidade (complexidade talvez nunca vista na história da literatura) em um recorte temporal limitadíssimo.

Além disso, Houaiss traduziu o livro em um momento em que a crítica ainda não havia dissecado a obra apropriadamente e muitas de suas características essenciais ainda não haviam sido elucidadas. O Ulysses Anotated, de Gifford, talvez a maior obra de referência ao Ulysses, ainda não havia sido publicado. A edição Gabler, projeto que reviu os originais do livro corrigindo erros tipográficos, e que hoje é considerada a edição definitiva, também não existia na época. Assim, além de levar a cabo a tradução do Ulysses sozinho e num espaço muito curto de tempo, Houaiss também não teve o auxílio de um aparato crítico apropriado, coragem que é louvável e que ao mesmo tempo isenta o tradutor de muitos dos ataques que ele poderia sofrer caso o livro tivesse sido traduzido vinte ou trinta anos depois.

Deve se sublinhar ainda as dificuldades que assombram qualquer tradutor que tente se aproximar do texto de Joyce. O texto é repleto de trocadilhos e de referências cruzadas que conferem ao Ulysses um certo grau de "intraduzibilidade". No primeiro episódio, por exemplo, Buck Mulligan diz: "Redheaded women buck like goats". A tradução direta da frase seria "As ruivas coiceiam como cabras". No entanto, o verbo buck (coicear) é utilizado claramente em sentido erótico e toma o posto, portanto, do verbo fuck (foder). Além disso, o verbo escolhido remete ao nome do personagem: Buck Mulligan. Essa é uma brincadeira que dificilmente não se perderá em uma tradução ${ }^{4}$.

\footnotetext{
${ }^{4}$ A tradução de Houaiss é “As ruivas fazem galinhagens como cabras” (p. 34).
} 
Em outro trecho, Stephen Dedalus, imerso em seus pensamentos, faz um trocadilho com seu nome: ele é Stephen the steel pen (a pena de aço). Um pouco adiante, Buck Mulligan, que vem rezando uma missa negra por todo o primeiro episódio, distribuindo bênçãos e frases bíblicas, emprega uma palavra composta dicionarizada bastante simples: dogsbody (corpo de cão) $)^{5}$ o que no contexto nos remete imediatamente a godsbody (o corpo de deus). Todos esses trocadilhos aparecem no primeiro episódio do livro e já dão uma noção do grau de dificuldade que o tradutor deverá enfrentar, uma vez que essas brincadeiras dificilmente poderão ser mantidas na tradução.

Assim, é importante enfatizar o quanto algumas críticas dirigidas à tradução de Houaiss devem ser relativizadas quando as dificuldades de trabalho, as dificuldades de acesso à fortuna crítica sobre o livro e as dificuldades intrínsecas ao texto são levadas em consideração. Passamos agora a abordar alguns problemas editoriais da tradução de Houaiss, problemas pelos quais o tradutor não deve ser responsabilizado, mas que prejudicam enormemente a fluência do texto em português.

O Ulysses é dividido em dezoito episódios que não tem numeração ou título. A despeito disso, os episódios são profundamente diferentes entre si, seja em questões técnicas ou estilísticas, seja quanto ao enredo, ao foco narrativo, aos personagens que participam da ação, etc. Os episódios do livro se distribuem em três partes: a parte I engloba os episódios de um ao três; a parte II vai do quarto ao décimo quinto; enquanto a parte III engloba os três últimos. E é na editoração gráfica dos episódios que surge o primeiro problema. A edição da Civilização Brasileira, afoita para economizar três ou quatro páginas na impressão final do livro, resolveu acumular todos os episódios, separando-os por apenas três linhas em branco ao invés de manter um espaçamento maior que permitisse ao texto uma apresentação mais higiênica. Com isso a editora cometeu um erro grave, induzindo os leitores não familiarizados com o texto a confundir as partes com capítulos, fazendo com que pensem que o livro tem apenas três grandes capítulos. Essa confusão entre partes e episódios pode ser muito danosa para uma primeira leitura do Ulysses e pode ser responsável pelo achatamento de diversas características específicas do livro. Em um livro tão variado (e difícil) como o Ulysses, agrupar os capítulos sem avisar o leitor é certamente doloso. No caso da passagem do segundo para o terceiro episódio, por exemplo, o caso é ainda mais grave uma vez que o episódio II termina na última linha de uma página e o episódio III começa na primeira da página seguinte. Ou seja: o leitor sequer percebe que passou de um episódio a outro. Além do acumulo de episódios, o livro não vem acompanhado de índice, o que contribui ainda mais para a confusão, tornando muito difícil manuseá-lo.

\footnotetext{
${ }^{5}$ No contexto, a palavra corpo é usada no sentido de cadáver ou corpo de pessoa morta. Por isso, a tradução de Houaiss nos parece bastante acertada: Canicarcaça.
} 
Infelizmente o pouco caso da editora não se restringe apenas à falta de índice e ao acúmulo de episódios; o texto também não conta com a tabela que nomeia cada um dos episódios do Ulysses de acordo com seu correspondente na Odisséia. Essa tabela havia sido elaborada pelo próprio Joyce alguns anos após a publicação do Ulysses, e é a responsável pela elucidação de muitos dos paralelos entre os dois textos. Desde que veio à luz, essa tabela passou a ser de presença quase que obrigatória nas edições do Ulysses e é, de fato, muito útil durante a leitura do livro. Os editores, no entanto, optaram por não imprimir a tabela, novamente privando seus leitores do direito de perceber o paralelo e comprometendo, assim, o bom desempenho do método mítico. Um leitor de primeira viagem do Ulysses que não possa conjurar a seu favor a tabela elucidativa dos paralelos, talvez nem sequer consiga entender porque o livro se chama Ulysses (título que remete diretamente a Odisseu).

Outro erro da mesma estirpe é a falta de aparato crítico da edição: não há prefácio, introdução, biografia, cronologia, ou qualquer outro tipo de paratexto que esclareça ao leitor do que trata o Ulysses, qual a sua importância, como ele deve ser lido. Soma-se a isso o fato de que praticamente não há notas elucidativas no livro. Nesse sentido, a edição da Editora Objetiva, cuja tradução é de Bernardina da Silveira Pinheiro, supera em muito a edição da Civilização Brasileira. Essa tradução mais recente conta não apenas com a tabela citada e com um estudo introdutório, mas também com um mapa de Dublin (útil para a fruição completa do romance), assim como muitíssimas notas elucidativas da tradução, do texto de Joyce ou do enredo. Uma vez que já elucidamos as condições de trabalho a que se submeteu Houaiss para traduzir o Ulysses, e que já levantamos as ressalvas que devem ser feitas à edição da Civilização Brasileira, passemos agora ao texto em si.

O texto joyceano é muito inventivo e para que sua inventividade se espelhe em outra língua é preciso que o tradutor seja audacioso. Esse certamente é um dos atributos da tradução de Antônio Houaiss,o que Augusto de Campos reconhece ao dizer que:

O motivo principal da excelência da tradução que Antônio Houaiss fez de Ulysses reside, a meu ver, na sua radicalidade. Entre verter simplesmente "as ideias" do texto, aclimatando-as ao "gênio" (ou fantasma?) "da língua portuguesa" e subverter o idioma para corresponder às invenções do original inglês, Houaiss optou pela última alternativa. [...] E foi isso mesmo que Houaiss soube compreender, partindo para uma tradução também "antinormativa", que revolve a língua e o leitor com o insólito de suas recriações vocabulares e sintáticas."

Em contraparte a essa audácia, porém, há pequenas dissonâncias no projeto tradutório de Houaiss, particularmente no que diz respeito às macro-estruturas do texto. A primeira delas é certamente a planificação da linguagem joyceana. Joyce normalmente trabalha com dois registros ex- 
tremos de linguagem: a erudição mais afiada caminha lado a lado com a fala vulgar. As marcas de coloquialidade em Joyce são muitas e muito frequentes, assim como a presença de gírias. A isso Joyce alia o gosto pela repetição sistemática de palavras e o uso de vocabulário elevado. Após todas essas misturas, o texto resultante orquestra em contraponto fala erudita e popular (no melhor gosto dos romances da segunda linha de que fala Bakhtin). Houaiss, no entanto, sistematicamente tende a achatar esses contrastes eruditizando-os. Houaiss tende a expurgar os vulgarismos do texto joyceano, e, quando os mantém, acaba criando uma oralidade artificial que não corresponde à naturalidade do original. Essa planificação nos parece um problema macro-estrutural grave do projeto do tradutor, já que deforma uma das facetas da obra. Vale fazer a ressalva de que no recorte do corpus por nós adotado o problema existe, mas um pouco minimizado, já que os três primeiros capítulos são dedicados a Stephen Dedalus e a eruditização de vocabulário levada a cabo por Houaiss funciona bem para esse trecho. Nos capítulos seguintes, contudo, o problema toma proporções maiores. É pela dificuldade do vocabulário empregado que a crítica normalmente costuma dizer que o Ulisses de Houaiss chega a ser mais difícil que o Ulysses de Joyce.

Outra prática que colabora para essa eruditização do vocabulário é a postura adotada por Houaiss na tradução das palavras compostas. Joyce cria, com frequência, neologismos compostos a partir de vocabulário corriqueiro, prática que é frequente em inglês, o que faz com que o leitor compreenda com facilidade essas palavras novas. Além disso, Joyce não as modifica muito: normalmente ele apenas não escreve o espaço entre elas. Assim, ele forma neologismos como fishgods (peixedeuses), dewsilky (orvalhosedoso), oxeyed (boiolhado).

Os compostos, no entanto, acabam se revelando um desafio para o tradutor para o português, pela simples razão de que essa operação não acontece da mesma forma nessa língua. A composição de palavras em português que sigam a mesma derivação morfológica do inglês gera produtos muito artificiais. Desse modo, para verter esse elemento do texto Houaiss apela para radicais gregos e latinos, o que dificulta bastante a compreensão de seus neologismos, tornando obscuro em português o que é cristalino em inglês. Assim, o tradutor verte os três exemplos citados acima como: piscideuses (fishgods), aljofarcetinado (dewsilky), oculivacuna (oxeyed). Certamente há traduções de compostos claras, como almiscarperfumado (muskperfumed), ou simsenhoreando (sirring), mas essa não é a regra. Em muitos casos o que era simples em inglês torna-se incompreensível em português, o que, novamente, contribui para a eruditização do texto.

Há de se fazer certas ressalvas, porém, quanto a essa maior dificuldade do texto, já que o texto homérico também é bastante difícil de se ler (para nós, assim como o era para os gregos). Algumas escolhas de 
Houaiss dão um certo ar de texto homérico à sua tradução, algo que certamente conta como ponto positivo. A tradução de lighshod hurrying feet por precipites pés lucífugos nos parece um bom exemplo desse tipo de aproximação.

Há ainda outra estratégia de Houaiss que nos parece bem acertada. $\mathrm{O}$ tradutor procura trabalhar com os conceitos de perda e compensação, o que o leva a tentar enriquecer o texto em determinado trecho para compensar uma perda significativa que se deu em outro. Isso ocorre da seguinte forma: no primeiro episódio, Houaiss não consegue manter uma das muitas aliterações presentes no original, wavewhite wedded words, que se perde completamente; no entanto, algumas sentenças depois, Houaiss traduz love's bitter mistery, em que não há aliteração alguma, por do amor o místico amargor. A recorrência das nasais e a assonância amor/amargor enriquecem o texto em português, compensando a perda anterior.

Ambas as estratégias listadas acima nos parecem congruentes e bem escolhidas, mas, infelizmente, são aplicadas com parcimônia.

Há também no texto de Houaiss uma série de pequenos erros de tradução que, embora fujam da perspectiva mais abrangente adotada por nós neste trabalho, merecem ser comentados. Entretante, vale ressaltar que dificilmente uma tradução, qualquer que seja, está isenta de erros. Além disso, as condições de trabalho de Houaiss certamente favorecem erros, uma vez que ele costurou o texto português numa era pré-Gifford e pré-Ulysses Annotated.

Dentre os erros menores podemos listar a tradução de familiar (inglês) por familiar (português). A palavra inglesa é um falso cognato e, na verdade, se refere a um daemon ou espírito protetor. É nesse sentido que ela é empregada por Stephen Dedalus no primeiro episódio. Outro erro aparece na tradução de plain, que normalmente significa plano ou simples, mas que, em Dublin no início do século, é uma gíria para cerveja. Houaiss, sem consultar o Ulysses Annotated, jamais poderia ter conhecido essa gíria de época, motivo pelo qual é automaticamente desculpado de seu erro. No entanto, a tradução dessa palavra é importante para a correta interpretação da canção Ballad of Joking Jesus que canta Buck Mulligan no primeiro episódio. Na canção de três estrofes, há ainda mais dois erros.

O primeiro é a versão do primeiro verso I'm the queerest young fellow that ever you heard por Bem raro, ao que sei, sou um rapazinho. A palavra queer desaparece na tradução, mas ela é essencial para que o leitor compreenda o tom do texto. Queer em inglês quer dizer esquisito, mas o termo tem uma conotação homossexual. É possível argumentar que na época em que o Ulysses foi escrito a palavra talvez não tivesse ainda assumido esse tom de questionamento sexual ${ }^{6}$. No entanto, esse não nos pa-

6 Como é o caso de gay, por exemplo. O termo só passou a designar homossexuais a partir dos anos cinqüenta. Até então era utilizado na acepção de alegre. 
rece ser o caso, já que um dos contos do primeiro livro de Joyce ${ }^{7}$, Dubliners, escrito em 1904, é inteiramente baseado na concepção homossexual dessa palavra.

Na canção, há ainda mais um erro de tradução. O último verso da primeira estrofe, So here's to disciples and Calvary foi vertido como Saúdes discípulos, saúde Calvário. No entanto, a expressão so here's to them, em inglês, é ofensiva (normalmente é acompanhada de um gesto). O equivalente em português seria aqui pra eles!, ou algo do gênero. A tradução de Houaiss, no entanto, sugere completamente o oposto, ao invés de ofender os discípulos e o Calvário, a tradução os saúda.

O mesmo tipo de modulação do significado do original se dá em outra fala de Buck Mulligan. No primeiro episódio, ao entrar na torre em que se encontram os outros personagens, a vendedora de leite comenta que o tempo está bom "graças a Deus". Mulligan (que celebra uma missa negra durante todo o episódio) ironiza a fala da mulher perguntando “Graças a quem?". Quando ela repete o que havia dito, Mulligan responde "Ah, to be sure". Essa fala é obviamente sarcástica e deveria ser traduzida como algo do tipo "Só pra ter certeza". No entanto, Houaiss escolhe "Ah, sim, tem razão", o que priva o texto traduzido da ironia herética de Buck Mulligan. Tal como está em português, ele concorda com a velinha, enquanto em inglês ele faz graça dela. Ao contrário dos outros erros apresentados até agora, esse nos parece ser voluntário, uma vez que não há dificuldade vocabular ou intertextual que justifique a mudança. $\mathrm{O}$ mesmo tipo de erro aparece novamente na imprecação pervertida de Mulligan: ao invés de usar a expressão cristalizada em inglês, Go to Hell!, o personagem blasfema novamente dizendo Go to God!. A escolha de God como substituto para Hell não é arbitrária e está de acordo com a postura herética de Mulligan. Houaiss, no entanto, decide por fim à brincadeira, traduzindo a fala como Vá para o Diabo!, escolha que anula o traço blasfemo.

Outro erro aparece um pouco mais adiante no texto, novamente numa das falas de Mulligan. Ao sair de casa, após ter tomado o café da manhã e ter comido pão com manteiga (butter, em inglês) Mulligan exclama And going forth he met Butterly (E adiantando-se ele encontrou amanteigadamente). Essa é uma referência paródica à flagelação de Cristo, texto que é registrado na Bíblia como, And going forth he wept bitterly (E adiantando-se ele chorou amargamente). Assim, há um trocadilho irônico entre as palavras bitter/butter. Houaiss não percebe a correspondência - ao que está aos nossos olhos, novamente, desculpado, já que não ti-

7 O conto se chama An Encounter, e o trecho em questão é (dois meninos estão andando num parque quando vêem um velho que, provavelmente, está se masturbando, e que logo se aproxima e, ao que parece, tenta abusar deles): "I say! Look what he's doing!" As I neither answered nor raised my eyes Mahony exclaimed again: "I say... He's a queer old josser!" 
nha acesso à fortuna crítica que elucidou tais casos, nomeadamente ao Ulysses Annotated. Sua tradução, E ao sair encontrou Butterly, por sua vez, quebra o sabor do original e introduz uma referência estranha para o leitor, já que, no texto em português, Butterly parece ser uma pessoa.

Há outros erros que transcendem essa análise miúda. Assim, como a eruditização do texto, nos parece que o texto de Houaiss sofre de mais um problema macro-estrutural. Ela nos parece carecer de algumas das amarras internas tão bem estabelecidas no texto em inglês.

No aperfeiçoamento do fluxo de consciência, Joyce cria uma técnica de "indução" dos pensamentos que pode ser acompanhada pelo leitor textualmente. No décimo episódio, por exemplo, o padre Conmee pensa: What was that boy's name again? Dignam, yes. Vere dignum et iustum est. O nome do personagem morto, Dignam, faz com que o padre lembre a citação latina Vere dignum et iustum est, devido à similaridade entre Dignam/dignum. Esse tipo de mecanismo indutivo é muito frequente (e aparece de várias formas) no Ulysses.

Encontramos uma dessas ocorrências no segundo episódio, em que Stephen Dedalus e Mr. Deasy conversam. Em certo momento, o senhor Dease diz: But I will fight for the right till the end. As palavras will fight, lembram Dedalus de uma música - For Ulster will fight - que aparece em fluxo de consciência imerso no discurso do narrador, sem qualquer nota explicativa. De acordo com o processo joyceano, o leitor tem que perceber esse encadeamento de ideias sozinho. $\mathrm{Na}$ tradução de Houaiss, porém, a fala do senhor Deasy é traduzida como Mas combaterei pelo direito até o fim, enquanto a música é traduzida como Porque Ulster lutará etc. Houaiss deveria ter traduzido as duas ocorrências de will fight por uma construção que surgisse, idêntica, duas vezes em português. Assim ele teria possibilitado ao leitor o encadeamento de ideias presente no original. A escolha de dois verbos diferentes, combaterá e lutará, se mostra contraproducente, uma vez que o leitor (que deve aprender sozinho como funciona o mecanismo) terá de deduzir uma conexão em português que é muito mais tênue do que a conexão no original. Assim, se o texto de Houaiss não acaba com a correspondência entre a fala do senhor Deasy e a memória de Dedalus, ele a dificulta bastante.

O mesmo se dá no terceiro episódio, em que Stephen, imerso em fluxo de consciência, lembra um verso de uma música cantada por Mulligan no primeiro episódio: And no more turn aside and brood. A música, popular entre os irlandeses, seria reconhecida imediatamente por um leitor (irlandês) do Ulysses. Destarte, o tradutor já tem de se haver com essa dificuldade inicial: nenhum leitor brasileiro reconhecerá a música. E, quando Stephen, na praia, lembrar-se de Mulligan cantando a música, na torre, o leitor brasileiro dificilmente perceberá a conexão. Houaiss complica ainda mais a compreensão do leitor ao traduzir diferentemente, no primeiro e no terceiro episódios, o mesmo verso. No primeiro a tradução é $\mathrm{Nem}$ 
mais a um canto ruminar, enquanto que no terceiro é Não mais a um canto ruminar. A modulação entre nem e não, admitimos, é pequena, mas essa pequena diferença, somada à dificuldade que o leitor brasileiro já tem $a$ priori, pode esfumaçar a ligação e torná-la opaca para o leitor de português.

O tradutor do Ulysses deve zelar por essas pequenas amarras que conectam um pensamento a outro (como no caso da conversa entre Dedalus e Mr. Deasy) ou um episódio a outro (no caso da música). Essas conexões são muitíssimo numerosas no Ulysses e são assustadoramente bem acabadas. Esse, inclusive, foi um dos motivos pelo qual a crítica levou quase sessenta anos para desenvolver um aparato crítico funcional para a obra. Citamos outro exemplo para que se tenha uma noção do quão violentas essas amarras podem vir a ser: no primeiro episódio, Buck Mulligan encontra na praia um amigo que lhe diz que Bannon (um fulano qualquer) está em outra cidade e arranjou uma namorada que chama de menina da fotografia. No quarto episódio, descobrimos que a filha de Bloom (o personagem principal) está trabalhando como assistente de fotógrafo em outra cidade. Setecentas páginas depois, no décimo quinto episódio, Bloom e Dedalus estão na região dos bordéis de Dublin quando um sujeito chamado Bannon aparece e pede aos dois desconhecidos uma camisinha. Bloom lhe entrega uma e o sujeito vai embora. Cabe, então, ao leitor relembrar as informações que foram oferecidas nos episódios um e quatro e somá-las à informação do episódio quinze, para compreender, sozinho, que o personagem em questão vai usar a camisinha, muito provavelmente, com a própria filha de Bloom, que tem apenas quinze anos. Cruzar essas informações é essencial para a apreciação correta da obra e, como nenhuma ajuda ou facilitação nos é dada por parte do autor, cabe ao tradutor mantê-las tais quais são e não dificultá-las ainda mais.

\section{Conclusão}

Ao fim desta investigação, nos sentimos confortáveis para exprimir nosso juízo de valor sobre o projeto tradutório de Houaiss. De um lado, sua tradução carrega, merecidamente, os louros de ter sido a primeira versão do Ulysses para o português e a grande responsável pela popularização da obra no Brasil. Além disso, Houaiss não se contentou em documentar a inventividade joyceana, mas tentou recriá-la, o que, aos nosso olhos, é mais um dos pontos positivos de seu trabalho. De modo geral, em sua batalha contra o titânico Ulysses, a tradução demonstra coragem e tenacidade. No entanto, de outro lado, a despeito de alguns erros de tradução a que estão sujeitos todos os tradutores, o projeto de Houaiss apresenta dois problemas macro-estruturais. 
O primeiro desses problemas se dá pela grande quantidade de laços narrativos que, embora muito bem resolvidos no texto original, não o estão na tradução. Apresentamos anteriormente alguns exemplos que intentam demonstrar como uma pequena modulação de significado na tradução pode obscurecer a compreensão do texto traduzido por parte do leitor. Infelizmente, em diversos pontos, o Ulysses parece ser menos consistente e menos amarrado em português do que em inglês. O segundo desses problemas é a planificação e o achatamento do texto de Joyce. Houaiss privilegia notavelmente a faceta erudita do Ulysses em detrimento da faceta popularesca e vulgar. No texto original, ambas têm o mesmo peso dentro do romance, enquanto que na tradução, o texto é muito mais empolado e, pode-se dizer, inclusive, vocabularmente mais difícil que o original. Além disso, a tradução acaba sendo prejudicada pelo projeto editorial precário da Civilização Brasileira, algo que escapa à responsabilidade de Houaiss, mas que acaba afetando também a apreciação do texto em português.

\author{
Áureo Lustosa Guérios Neto \\ aureolgneto@gmail.com \\ Universidade Federal do Paraná
}




\section{Referências Bibliográficas}

BAKHTIN, Mikhail Mikhailovitch. O discurso no romance in Questões de literatura e de estética: a teoria do romance. São Paulo: Unesp e Hucitec, 1988.

CAMPOS, Augusto de; CAMPOS, Haroldo de. Panaroma de Finnegans Wake. São Paulo: Comissão Estadual de Literatura, Secretaria da Cultura, 1962.

ELIOT, T. S. "Ulysses, 'Order and Myth"' in Selected Prose of T. S. Eliot. London: Faber and Faber, 1975.

GALINDO, Caetano Waldrigues. Abre aspas: a representação da palavra do outro no Ulysses de James Joyce e seu possível convívio com a palavra de Bakhtin. Tese de doutoramento. Universidade de São Paulo, orientador: José Luiz Fiorin, 2006.

GIFFORD, Don; SEIDMAN, Robert J. Ulysses Annotated. Berkeley: University of California Press, 1989.

JOYCE, James. Ulysses. New York: Everyman’s Library, 1997.

. Ulisses. Trad. de Antônio Houaiss. Rio de Janeiro: Civilização Brasileira, 2005.

- Ulisses. Trad. de Bernardina da Silveira da Pinheiro. Rio de Janeiro: Objetiva, 2005. 